\title{
Functional and ecological aspects of the mucus trails of the intertidal prosobranch gastropod Littorina littorea
}

\author{
M. Edwards*, Mark S. Davies \\ Ecology Centre, University of Sunderland, Sunderland SR1 3SD, United Kingdom
}

\begin{abstract}
It has been suggested that some gastropods might utilise pedal mucus trails as a source of nutrition. Despite much work, there has been little attention on the ecological consequences of such a strategy. Here we aimed at determining the value of mucus trails to snails by investigating (1) snail reaction to naturally aged conspecific mucus trails and (2) the effect of starvation on trailfollowing behaviour. The mucus trails of Littorina littorea (L.) adhered microalgae in the laboratory but this ability began to diminish after the trails had been exposed on-shore for $>1$ tidal cycle. Natural floral components of trails were greatest for up to 4 tidal cycles of exposure and then began to diminish. If trails are to be used for foraging purposes, snails would gain most benefit by utilising them while relatively fresh. Correspondingly, snails readily responded to fresh mucus trails, but after 20 tidal cycles only 3 of 24 did so. As the mucus was still present we conclude that some unknown cue is present enabling snails to discriminate trails by their age. Despite previous work to the contrary, no evidence of preference for following trails in a particular direction was found and we conclude that trail following in our snails was not related to mate searching or the formation of aggregations. The starvation level of snails (up to $4 \mathrm{~d}$ ) did not affect their foraging behaviour in the laboratory. However, snails followed the trails of starved snails for significantly shorter distances than those of fed snails, suggesting a coding of starvation level in the trail mucus. Choices about whether to trail follow may be based on how well fed a conspecific is and how old a trail is - following a fresh trail would increase the likelihood of encountering a conspecific and may have a nutritional benefit if the trail is to be grazed. Previous work on trail following should be re-evaluated in the light of these findings.
\end{abstract}

KEY WORDS: Trail following $\cdot$ Foraging $\cdot$ Mucus $\cdot$ Littorina littorea $\cdot$ Behaviour $\cdot$ Microalgae

\section{INTRODUCTION}

In many marine gastropods, a large proportion of consumed energy is expended in the production of pedal mucus (e.g. $23 \%$ in Ilyanassa obselata, Edwards \& Welsh 1982; 23 to $29 \%$ in Haliotis tuberculata, Peck et al. 1987; $31 \%$ in Patella vulgata, Davies et al. 1990; see Davies \& Hawkins 1998 for a review). As a locomotory method, the use of pedal mucus is considered to be the costliest, $\sim 12$ times greater than that of a run-

${ }^{*}$ Present address: CLSM, Porter Building, University of Newcastle, Newcastle-upon-Tyne NE1 7RU, UK.

E-mail: m.edwards@ncl.ac.uk ning organism of comparable size (Denny 1980). Postdeposition functions of mucus have been sought to explain how such a costly method of locomotion can be energetically viable. Many have been considered, ranging from the use of mucus trails in aggregating and finding a mate (Chelazzi 1990, Erlandsson \& Kostylev 1995), to navigating to a home scar (Chelazzi et al. 1983, 1987, Denny 1989), finding food (Hawkins \& Hartnoll 1983, Davies \& Beckwith 1999) and increasing grazing success by the adhesion of algal particles to the mucus trail (Connor \& Quinn 1984, Connor 1986, Davies et al. 1992a). Some gastropods re-ingest the mucus trail, it is suggested, to regain some of the energy used in laying it (Calow 1974) as mucus can 
provide, through its gradual breakdown, a source of bacterial nutrition (Peduzzi \& Herndl 1991).

Most studies, however, have focused on establishing the means by which the energy expended in mucus can contribute to animal function, rather than determining the practical ecological consequences of any strategy of energy recoup. Our study focused on Littorina littorea (L.) and was aimed at determining the value of mucus trails to snails by investigating (1) how this animal reacts to naturally aged conspecific mucus trails and (2) the effect of starvation on trail-following behaviour. Starting with the premise that mucus trails might be used in provendering, we determined the potential of mucus trails to supply nutrition: their ability to bind food (algal) particles in situ and how the stickiness of the trails for microalgae varies with time. To complement this we determined how snails might utilise these trails: their behaviour when encountering weathered trails. Finally we considered that if trails are used nutritionally then starvation may be a factor mediating trail use: how starvation affected trailfollowing behaviour.

We chose to use the intertidal prosobranch Littorina littorea because of the wealth of data already accumulated on its physiology and behaviour (including cost of mucus production, Davies et al. 1992b) and because of its widespread distribution on many shorelines across Europe, from the North Sea to the Mediterranean (Campbell 1994). Locally it ranges from the upper shore into the sublittoral, and occurs in estuaries and mud flats as well as on rocky shores. Lein (1980) considered L. littorea to be among the most important herbivores in the littoral zone. From an energetic perspective, it is important that littorinids locate food without excessive searching (Norton et al. 1990), as the production of trail mucus is expensive and oxygen consumption is 15 times higher when crawling than when at rest (Newell 1970). The food of $L$. littorea comprises macroalgae and microalgae, and the strong seasonal cycles in food abundance (Castenholz 1961, Hill \& Hawkins 1991) makes starvation a distinct possibility for L. littorea. Starvation has been shown to prompt a change in foraging strategy in other marine gastropods (Morton et al. 1995, Morton \& Chan 1999). In L. littorea, preliminary experiments by Newell (1958) showed that starved snails, once they had encountered and eaten food, made longer feeding excursions below water.

Mucus trails of Littorina littorea are also important as carriers of information to conspecifics. Erlandsson \& Kostylev (1995) noted that the sex of the trail layer (marker snail) could be 'read' by conspecifics. Davies \& Beckwith (1999) observed that an indication of 'self' was coded. Davies \& Knowles (2001) showed that trails containing a dilute extract of a trematode parasite could be detected. If snails were able to determine the age of the trails, their relative use could be evaluated. For example, an old (days) trail might not be worth following if mating were the motive.

We formulated the following hypotheses:

(1) That, over time, naturally aged mucus trails of Littorina littorea become less able to bind microalgae in the laboratory and in situ; also, that the adhesive ability of the mucus differs across the width of the mucus trail. J. Blackwell (unpubl.) has shown trails to have a convex profile, $\sim 15 \mu \mathrm{m}$ at the edges and $\sim 25 \mu \mathrm{m}$ in the centre.

(2) That the behaviour of $L$. littorea in response to the mucus trails is altered as the trails age.

(3) That starvation in L. littorea (up to $10 \mathrm{~d}$, Newell 1958) affects its foraging behaviour; also, that $L$. littorea responds behaviourally to starvation state in the mucus trails of conspecifics.

\section{MATERIALS AND METHODS}

Snail storage. Littorina littorea were collected from Whitburn, on the north-east coast of England (national grid reference NZ 414 616), and maintained in the laboratory for a maximum period of $3 \mathrm{~d}$. The snails were kept in a tank of aerated seawater at $\sim 10^{\circ} \mathrm{C}$. Approximately $500 \mathrm{~g}$ of seaweed (Fucus sp.), collected at the same time from Whitburn, was kept with snails. The snails were kept in the same room as the study area to minimise temperature fluctuations during transfer from storage to study. The investigations were conducted between November 1998 and March 1999, outside of the main breeding season of L. littorea (Grahame 1973) in order to avoid snail sexual state as a confounding factor.

Experimental procedure. Ability of aged mucus trails to bind microalgae in the laboratory and in situ: Individual snails (length 20 to $25 \mathrm{~mm}$ ) were placed singly on microscope slides submerged in fresh filtered $(2 \mu \mathrm{m})$ and UV sterilised seawater. A mucus trail of approximately 12 to $14 \mathrm{~mm}$ width and 40 to $50 \mathrm{~mm}$ length was laid along the length of the slide. Seventy such trails were produced from 70 animals. The slides were contained within a wooden tray, covered in plastic mesh ( $5 \mathrm{~mm}$ pores) to allow seawater access to the slides but to prevent grazer ingress. This slide tray was secured to the shore at $2 \mathrm{~m}$ above chart datum (mid- to high shore) in a disused harbour at Sunderland Docks (NZ 416 571). Tides were semi-diurnal.

Seven treatments were created where duration on the shore was the variable. The treatments were $0,1,2$, $4,6,10$ and 20 tidal cycles. Periods greater than this were not investigated because by this time half the mucus is likely to have decayed (Davies et al. 1992a). For each treatment, 10 slides were selected at random, removed from the slide tray and returned to the labo- 
ratory. In each case this was done immediately after the tide had retreated far enough, so that dehydration of mucus was minimised. The 10 slides were placed in filtered and UV sterilised seawater for $1 \mathrm{~h}$ to allow rehydration of the mucus present on the slides (Davies et al. 1992c). Slides from the 0 tidal cycles treatment were removed immediately after the tray had been fixed to the shore.

As an index of the adhesive properties of the mucus trail, Amphora coffeaeformis Agardh were allowed to adhere to the trails. A. coffeaeformis is a benthic, raphed pennate diatom (length 15 to $25 \mu \mathrm{m}$ ) and is a common component of the microflora of the benthos (Round et al. 1990). It is motile and secretes mucus that is probably associated with locomotion (Round et al. 1990). For each treatment, 5 slides were submerged for 30 min in a suspension of A. coffeaeformis in ErdSchreiber medium (Føyn 1934) at $10^{5}$ cells ml $^{-1}$. On fresh trails, this produced a film of diatoms on the mucus at densities similar to natural densities found in the rocky benthos (Hill \& Hawkins 1991, Davies et al. 1992a, Davies \& Beckwith 1999). The remaining 5 slides were placed in filtered seawater for $30 \mathrm{~min}$. After this period, the 2 sets of slides were rinsed gently in filtered seawater and fixed wet for $12 \mathrm{~h}$ : in an air-tight container slides were placed above a solution of $25 \%$ (v/v) glutaraldehyde. No coverslip was applied to prevent damage to the mucus trail.

The number of microalgae adhering to each slide was counted at $10 \%$ (towards one edge of the trail), $50 \%$ (the centre of the trail) and 90\% (towards the other edge of the trail) across the width of the mucus trail. This was replicated 3 times along the length of each mucus trail, at random distances apart, with the proviso of a minimum separation of $10 \mathrm{~mm}$. Each algal count was made over an area of $2 \mathrm{~mm}^{2}$, a $1 \times 2 \mathrm{~mm}$ rectangle.

Response by Littorina littorea to ageing mucus trails: L. littorea laid 168 trails on microscope slides as previously described, and the polarity of the trails was noted. Three mesh-covered slide trays, each holding 56 slides, were secured to the shore at $2 \mathrm{~m}$ above chart datum at the disused harbour. The 3 slide trays were spaced 100 to $150 \mathrm{~m}$ apart.

The same periods of tidal immersion were used. On each sampling, 8 slides from each site were randomly selected and rehydrated in the laboratory for $1 \mathrm{~h}$. After rehydration, each slide was placed next to a clean microscope slide under $\sim 6 \mathrm{~mm}$ of filtered seawater. One Littorina littorea was placed on the clean slide, facing the treatment slide such that it proceeded at $90^{\circ}$ to the path of the mucus trail. If a snail responded to the mucus (indicated by a change in direction) then the polarity of this motion was noted.

Effect of starvation on the trail-following behaviour of Littorina littorea: Following snail storage, 4 starva- tion levels were established. Snails were starved for 0 , 2,5 and $10 \mathrm{~d}$. The period of 0 to $10 \mathrm{~d}$ was chosen to reflect the period chosen by Newell (1958). Shells and opercula were scrubbed with a coarse nylon brush, in an attempt to remove algae that may be eaten by other snails. Each snail was then numbered with correcting fluid and placed in a second tank of filtered and sterilised, aerated seawater for the allocated period. Snails in the starvation level of $0 \mathrm{~d}$ were also scrubbed, numbered and placed in the filtered and sterilised seawater tank for 30 min prior to use.

In this trail-following study, snails were designated as markers or trackers. For each experimental trial, the marker snail was the first snail in the trial. The tracker was the snail placed on the starting point of the previous (marker) snail. Each snail was subjected to one of the 4 starvation levels and used (only once) as either a marker or a tracker snail, creating 16 experimental treatments, in a crossed design. Each treatment (e.g. marker $0 \mathrm{~d}$ : tracker $0 \mathrm{~d}$ ) had 10 replicates and the experimental order was randomised.

Trials took place in a $0.6 \times 0.6 \mathrm{~m}$ glass arena with glass sides, supported at its corners. The sides of the arena were covered in black polyethylene sheets and the entire area, including the floor, was surrounded in black polyethylene sheets to remove visual clues for orientation. Ten fluorescent 'cool white' tubes were positioned directly $0.5 \mathrm{~m}$ above the square arena to flood the area with light ( $\sim 58 \mu \mathrm{E} \mathrm{s}^{-1} \mathrm{~m}^{-2}$ at the surface), in an attempt to remove light biases.

A sheet of glass, $0.5 \times 0.5 \mathrm{~m}$, was submerged in filtered and sterilised seawater in the arena, at a depth of $12 \mathrm{~mm}$. A marker snail was placed centrally on the glass sheet. No time limit was imposed and the snail was observed until it left the glass sheet. The movement of the snail was recorded onto videotape, using a camcorder positioned underneath the arena. The glass sheet was removed from the arena and the filtered seawater was replaced with fresh filtered seawater. This reduced the possibility of chemical cues being present in the seawater to bias the behaviour of the tracker snail. The glass sheet was returned to the arena and a tracker snail was introduced. The movements of the tracker snail were similarly recorded, until the snail left the glass sheet.

After each trial, the glass sheet was removed from the arena, wiped dry (dislodging mucus present) and cleaned with $95 \%(\mathrm{v} / \mathrm{v})$ ethanol. The sheet was then rinsed in filtered seawater twice and wiped dry.

The movements of the snails were traced from a video monitor onto acetate sheets. Comparisons of linear distances in the arena with distances on different areas on the monitor screen (the edges were particularly scrutinised) revealed a consistent scaling factor of 2.5. The following measurements were taken: time 
taken for marker to reach the edge of the glass; total distance travelled by marker within the time period; direct distance from starting point to end point (as the

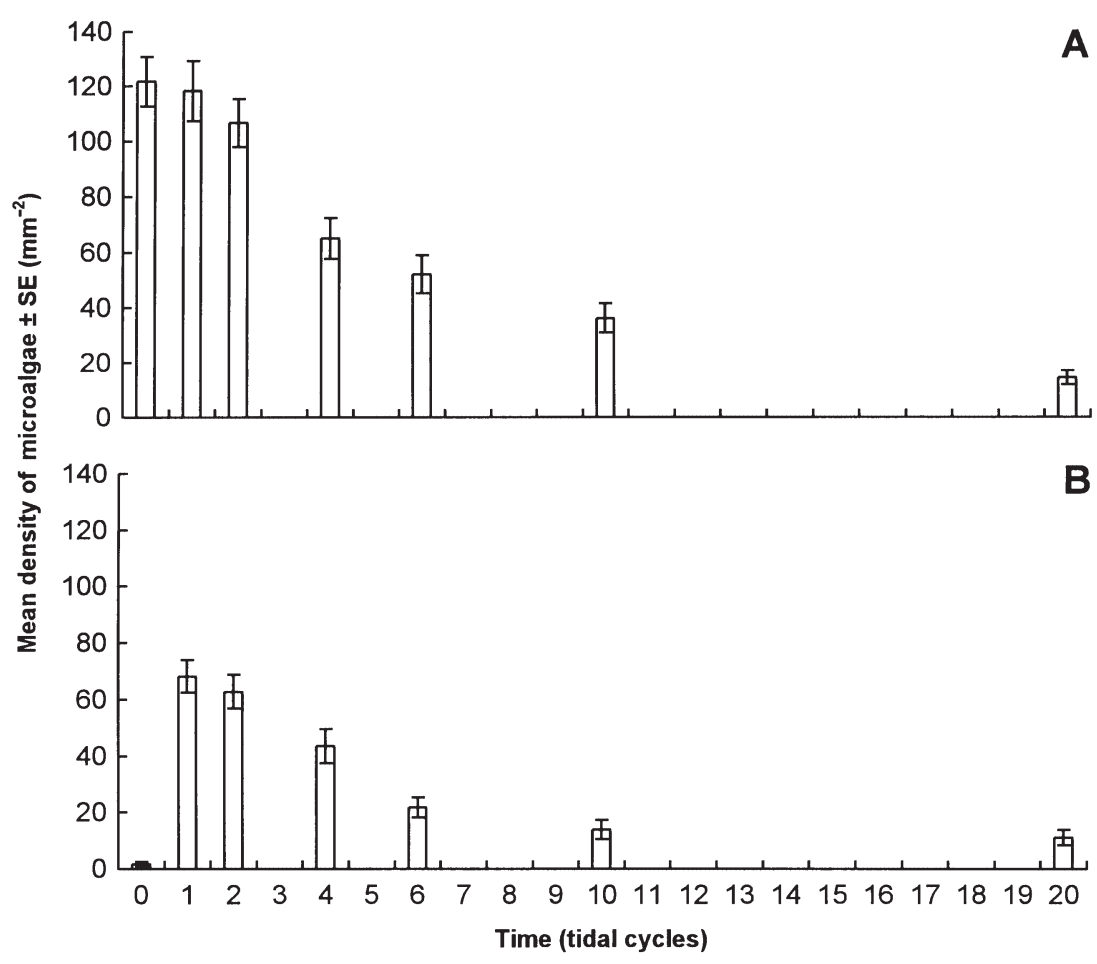

Fig. 1. Microalgal densities on naturally aged mucus trails that (A) were submerged in a suspension of Amphora coffeaeformis and (B) were submerged in filtered seawater. Both treatments were subjected to natural colonisation of microalgae while on the shore

Table 1. Three-factor ANOVA on counts of microalgae in mucus trails. Tukey tests on the factor time: $1,+$ microalgae $; 2,-$ microalgae. Underlines indicate means that are not significantly different

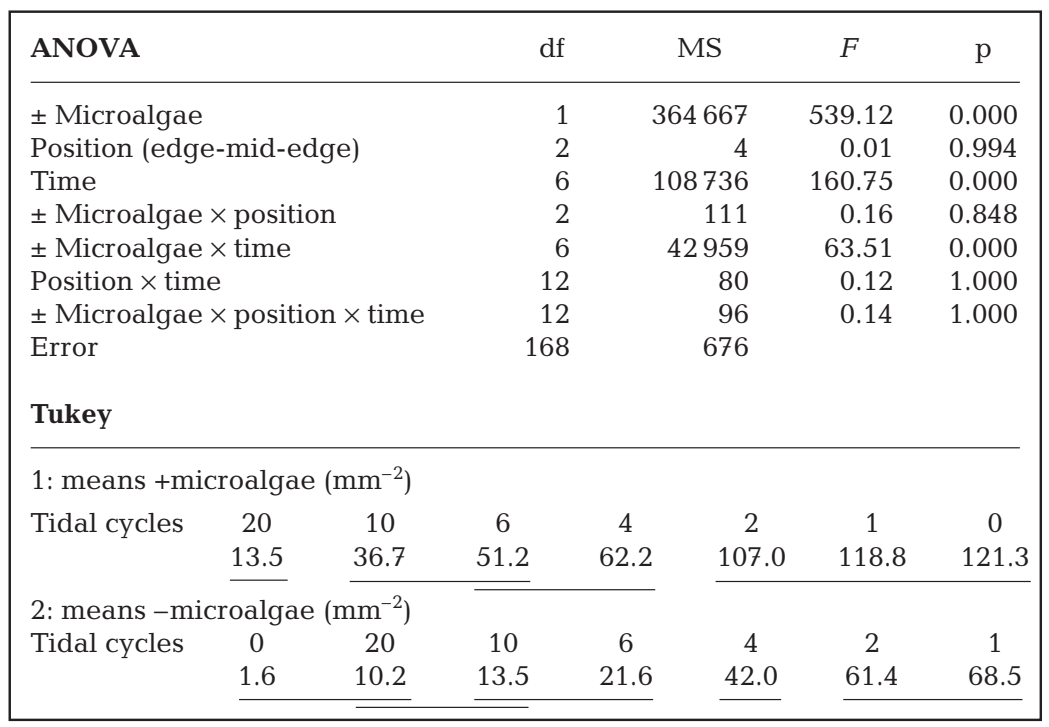

snail left the glass) of marker; distance of trail following of self (in marker); and distance of trail following of marker by tracker snail. Calculated for markers were the following: speed (total distance divided by total time); self coincidence index (marker trail following distance divided by marker total distance); and tortuosity index (TI) of the marker (direct distance divided by total distance). Tracker data were used to calculate the coincidence index (tracker distance trail following of marker divided by marker total distance). A coincidence index of 1 indicates that the snail followed the trail of the marker snail completely, whereas a value of 0 indicates that the snail did not follow the trail of the marker at all. A TI of 1 indicates that the snail took a straight line to the edge of the glass sheet, and did not deviate from this. Values approaching 0 indicate increasingly tortuous paths.

\section{RESULTS}

\section{Ability of aged mucus trails to bind microalgae in the laboratory and in situ}

The data were normally distributed and homoscedastic allowing parametric analysis. Over the whole experiment, the ability of mucus to retain microalgae was reduced significantly with increasing tidal exposure (Fig. 1, Table 1). For each level of tidal exposure, a greater mean density of algae was recorded on the treatments submerged in Amphora coffeaeformis (+ microalgae) than those not submerged (- microalgae). The significant interaction term in Table 1 was predominantly owing to the 0 tidal cycle level of the 'time' factor (Table 1), which differed markedly in its response to the ' \pm microalgae' factor owing to the experimental design. When the mucus trails were submerged in the suspension of A. coffeaeformis, there was a significant reduction in the density of microalgae adhering to the mucus trail after only 2 tidal immersions (Fig. 1, Table 1), i.e. the adhesive properties of fresh mucus trails per- 
sisted for over 2 tidal cycles. There was a further significant reduction after 10 tidal immersions. After 20 tidal immersions, the density of microalgae was reduced nearly 3 -fold over that after 10 tidal immersions and by $\sim 9$ times over that of fresh mucus.

Natural colonisation by microalgae (trails not submerged in the suspension of Amphora coffeaeformis) also was not significantly reduced until after the second tidal immersion (Fig. 1, Table 1). Clearly, after initial colonisation by microalgae in the first 1 to 2 tidal cycles, the longer mucus remains on the shore, the lower its microalgal complement. Adhesion of microalgae to trails is not a cumulative process over the periods examined; rather, there is an initial adhesion followed by loss of microalgae (Fig. 1). Further, the ability of the mucus to bind microalgae diminishes over time.

Position across the trail had no significant effect on the density of microalgae at the 3 sites examined (10\%, $50 \%$ and $90 \%$ across the trail width).

\section{Response by Littorina littorea to ageing mucus trails}

The data were not normally distributed and were analysed using non-parametric tests. There was no sig-

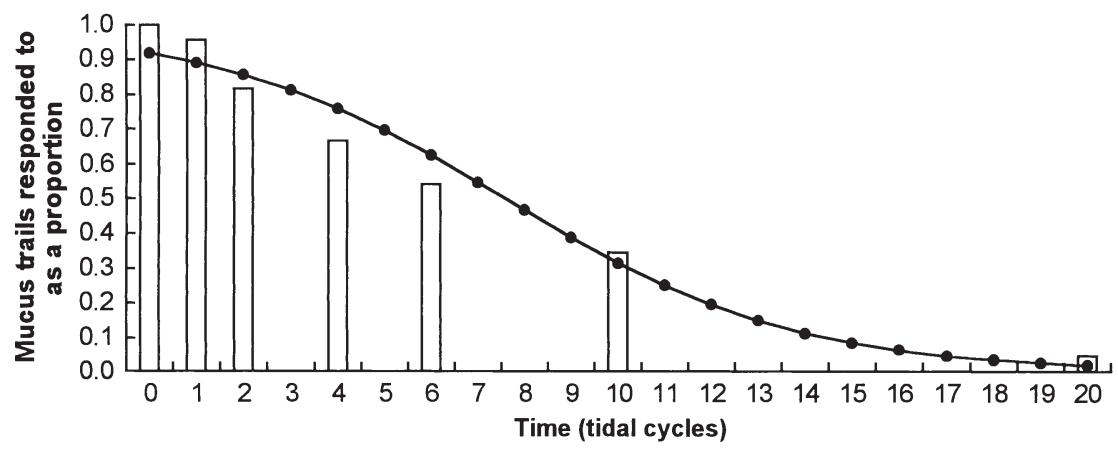

Fig. 2. Proportions of mucus trails responded to by a conspecific (bars). Line represents binary logistic regression. Data were pooled from the 3 sampling sites $(\mathrm{n}=24$ in each case)

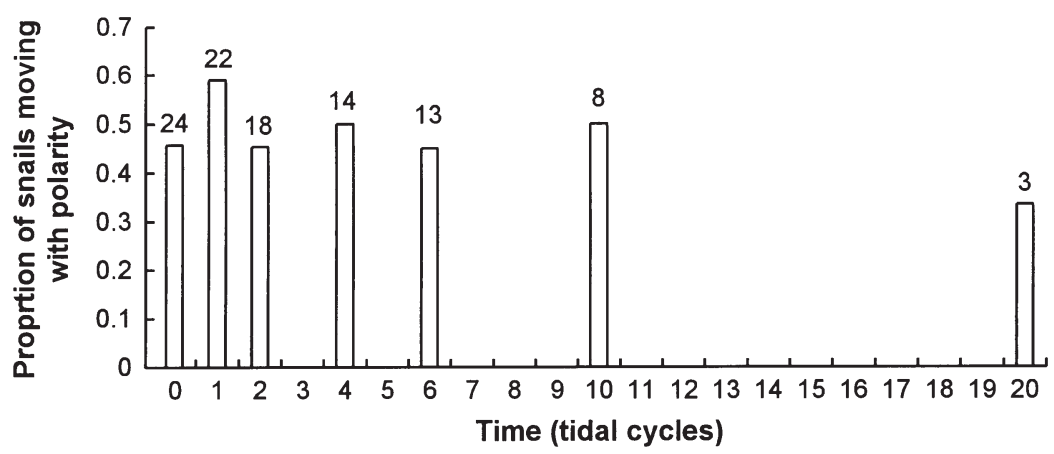

Fig. 3. Proportions of snails that followed the marker trail 'with polarity'. Data were pooled from the 3 sampling sites. Numbers above bars are sample sizes
Table 2. Binary logistic regression on the response of snails to mucus trails after different periods of tidal exposure. Loglikelihood $=-67.322$; test that all slopes are 0: $G=73.091$, $\mathrm{df}=1, \mathrm{p}=0.000$

\begin{tabular}{|lrrrc|}
\hline Predictor & Coefficient & SD & $Z$ & $p$ \\
\hline Constant & 2.4343 & 0.3664 & 6.64 & $<0.001$ \\
Time & -0.3211 & 0.0559 & -5.75 & $<0.001$ \\
\hline
\end{tabular}

nificant effect of the location of the slide trays (binary logistic; site 1 versus site $2, Z=-0.46, p=0.638$; Site 1 versus Site 3, $Z=-0.69, \mathrm{p}=0.493$; Site 2 versus Site 3, $Z=-0.22, \mathrm{p}=0.822$ ) and so the data were pooled with respect to location. There was, however, a significant decrease in the proportion of mucus trails responded to as tidal exposure increased (binary logistic, $Z=-5.75$, $\mathrm{p}<0.001$; Table 2, Fig. 2).

Owing to the great loss of response after 10 and 20 tidal cycles (giving only 8 and 3 responses from 24, respectively), only the first 5 tidal cycle treatments were analysed for polarity choice. There was no significant change in polarity choice (either with or against polarity) over increasing tidal exposure (binary logistic, $Z=0.46, \mathrm{p}=0.647$; Fig. 3). There was also no significant difference in polarity choice between the 3 sites. There was no evidence to suggest that trail following in one direction (with or against polarity) was preferred.

\section{Effect of starvation on the trail-following behaviour of Littorina littorea}

Marker snails had only their own mucus trails present in the arena. Tracker snails had a mucus trail of a conspecific present. Therefore, the marker snails yielded behavioural information concerning starvation levels in the absence of conspecifics and their mucus trails, and trackers yielded behavioural information concerning starvation levels in the presence of conspecific mucus.

For the marker snails, data were pooled into groups according to starvation level $\left(\mathrm{n}=40\right.$ group $\left.^{-1}\right)$. The data in each case were normally distributed and homoscedastic allowing parametric analysis. There was no significant difference in the mean distances trav- 

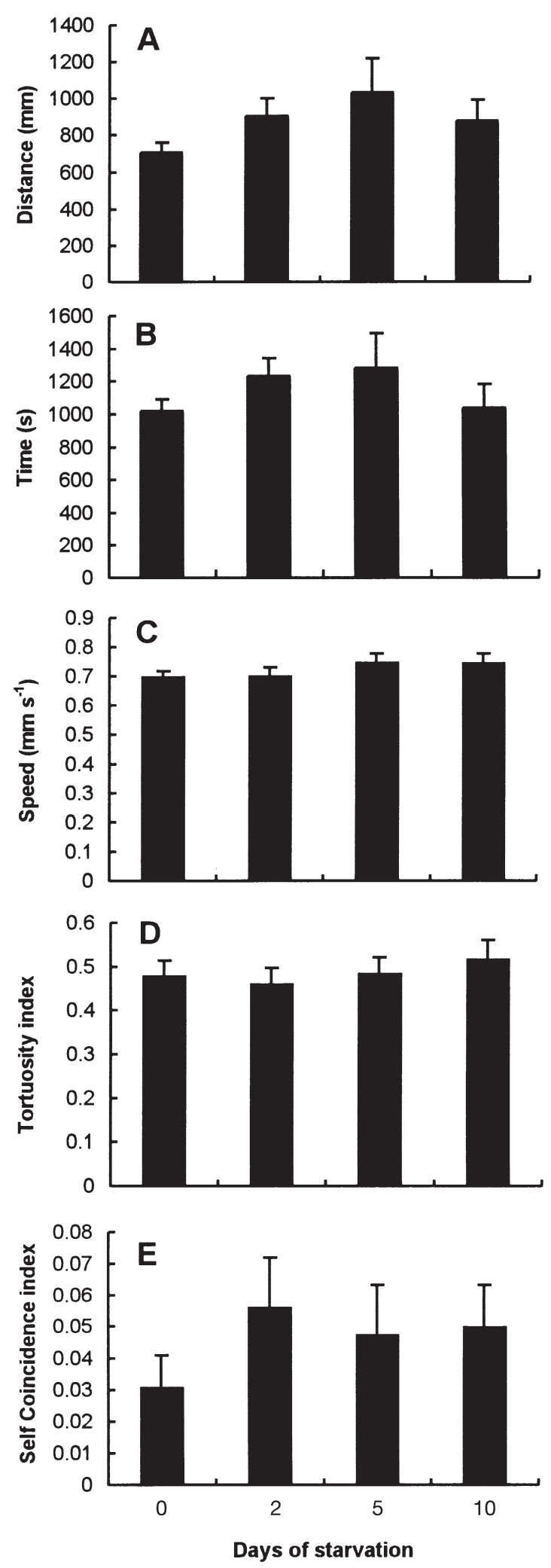

Fig. 4. Behaviour of marker snails in starvation study. (A) Total distance travelled; (B) time taken; (C) speed; (D) tortuosity index; (E) self coincidence index. Values are means ( \pm standard error $[\mathrm{SE}]), \mathrm{n}=40$ elled by Littorina littorea when subjected to different starvation levels, in the absence of conspecific mucus $(F=0.37, \mathrm{p}=0.771 ;$ Fig. 4A). Typically, snails travelled for $\sim 0.7$ to $1.0 \mathrm{~m}$ on the glass sheet. The minimum distance was $0.3 \mathrm{~m}$ ( $0 \mathrm{~d}$ starved) and the maximum distance was $2.8 \mathrm{~m}$ ( $5 \mathrm{~d}$ starved).

Also, in the absence of conspecific mucus, there was no significant difference in the mean periods spent travelling by Littorina littorea in relation to the 4 starvation treatments $(F=0.63, \mathrm{p}=0.596$; Fig. $4 \mathrm{~B})$. Snails travelled for $\sim 1000$ to $1200 \mathrm{~s}(\sim 17$ to $20 \mathrm{~min})$ before reaching the edge of the glass sheet. The minimum period on the glass was $300 \mathrm{~s}$ (0 d starved) and the maximum was $3536 \mathrm{~s}$ ( $1 \mathrm{~h})$ (5 d starved).

Given that there was no significant difference in distance or time spent travelling by Littorina littorea within the 4 treatments, there was no significant difference in the speed $(F=0.93, p=0.427$; Fig. $4 \mathrm{C})$. The snails travelled at $\sim 0.7$ to $0.75 \mathrm{~mm} \mathrm{~s}^{-1}$. The minimum speed was $0.41 \mathrm{~mm} \mathrm{~s}^{-1}$ ( 2 d starved) and the maximum speed was $1.51 \mathrm{~mm} \mathrm{~s}^{-1}$ (also 2 d starved).

The mean TI also showed no significant variation between the 4 starvation treatments $(F=0.35, \mathrm{p}=0.791$; Fig. 4D). The mean TI of the 4 treatments ranged from $\sim 0.45$ to $\sim 0.5$. There was great variability in the tortuosity: the lowest TI (the most tortuous trail) was 0.03 (5 d starved) and the highest TI (the least tortuous trail) was 0.97 (10 d starved).

Most snails $(\sim 70 \%)$ did not attempt self trail following, creating a data set that was not normally distributed. The arcsine square root transformation normalised the data. The degree of marker self trail following did not show significant differences in relation to the 4 starvation levels ( $F=0.35, \mathrm{p}=0.792$; Fig. $4 \mathrm{E})$. Snails tended to have low mean self coincidence indices, ranging from $\sim 0.03$ to $\sim 0.05$. The greatest self coincidence index was 0.35 ( $0 \mathrm{~d}$ starved) and the smallest self coincidence index was 0 , shown by most snails in each of the treatments.

The tracker snails were presented with a conspecific mucus trail whose length was not a fixed value. Thus, measurements such as total distance, time, speed and TI were not recorded for trackers as they may be influenced by the behaviour of the marker. Analysis of tracker data was confined to the coincidence index. The starvation level of the tracker snail had no significant effect on the quantity of trail following (Fig. 5, Table 3). The level of starvation of the marker snail did, however, have a significant effect on the quantity of trail following by the tracker snail $(F=3.22, \mathrm{p}<0.05$; Fig. 5, Table 3). Snails therefore can detect and do respond to information in the trail concerning the level of starvation of its layer. Snails followed trails of conspecifics starved for $10 \mathrm{~d}$ significantly less than those trails laid by snails starved for $2 \mathrm{~d}$, or snails that had not 


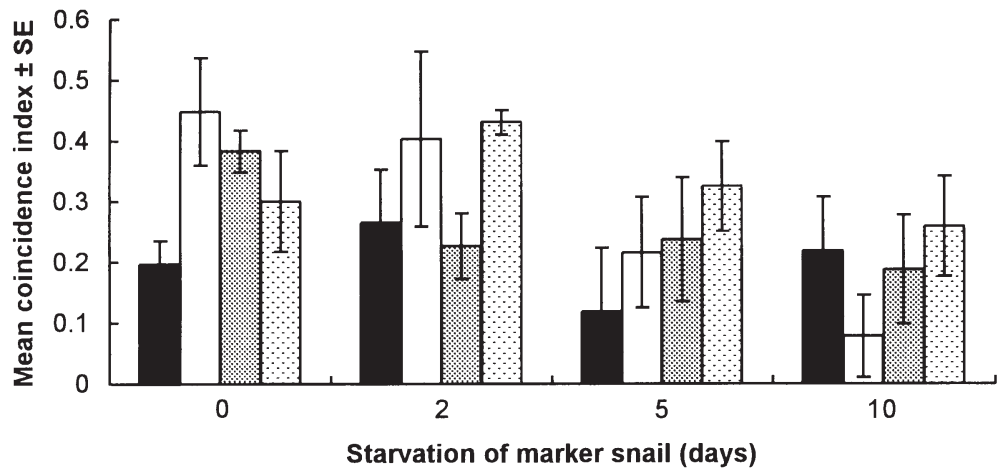

Fig. 5. Coincidence indices of Littorina littorea with respect to marker and tracker starvation levels. For tracker snails, black bars represent $0 \mathrm{~d}$ starvation, white bars $2 \mathrm{~d}$, grey bars $5 \mathrm{~d}$, stippled bars $10 \mathrm{~d}$ starvation contribute to the degradation of mucus (Herndl \& Peduzzi 1989, Peduzzi \& Herndl 1991). The loss in microalgal density as reported here is probably associated with the degradation: a loss in the ability of mucus to retain microalgae over time, or direct mechanical loss of mucus and the microalgae it contains. A similar loss in adhesive ability was reported by Davies \& Beckwith (1999) working on the same system. They observed a loss of adhesion after 5 to $8 \mathrm{~h}$ of immersion in a microalgal suspension and ascribed this to mucus decay. Davies et al. (1992a) reported a half-life of Littorina littorea pedal mucus of $\sim 12 \mathrm{~d}$. Here, after $10 \mathrm{~d}$ (20 tidal cycles), the density of microalgae within the (-microbeen starved. There was $\sim 1.8$ times more trail following after $0 \mathrm{~d}$ of starvation than after $10 \mathrm{~d}$ of starvation. After $2 \mathrm{~d}$ of starvation, there was $\sim 1.6$ times more trail following than after $10 \mathrm{~d}$ of starvation.

\section{DISCUSSION}

Fresh pedal mucus trails are sticky and can retain artificially applied microalgae (Fig. 1). The shore environment reduces the mucus's sticky properties, but only significantly so after more than 2 tidal cycles of exposure (1 d). During the first tidal cycle after a mucus trail is produced it gains a microfloral component at a level that is sustained until after 2 tidal cycles. Trail mucus is able both to collect potential food material for littorinids and to sustain a microalgal community, but these diminish with weathering. If mucus is to be used as a provendering agent then, in the environment we used, snails should prefer to feed on trails that are $1 \mathrm{~d}$ old or less. Both wave action and microbial attack

Table 3. Two-factor ANOVA on the coincidence index of Littorina littorea in relation to the starvation level of both marker and tracker snails. Data were square root arcsine transformed prior to analysis. Tukey test on marker snails. Underlines indicate untransformed means that are not significantly different

\begin{tabular}{|lrccc|}
\hline ANOVA & df & MS & F & p \\
\hline Marker & 3 & 0.22427 & 3.22 & $<0.05$ \\
Tracker & 3 & 0.11647 & 1.67 & $>0.05$ \\
Interaction & 9 & 0.07822 & 1.12 & $>0.05$ \\
Error & 144 & 0.06971 & & \\
Tukey & & & & \\
\hline Means, marker snails & & & & \\
Length of starvation (d) & 10 & 5 & 2 & 0 \\
& 0.186 & 0.224 & 0.296 & 0.332 \\
\hline
\end{tabular}

algae) mucus trail had undergone a 6-fold decrease since the first tidal cycle. However, comparisons are difficult as location is different.

The mucus trails exposed on-shore were not saturated with microalgae: more could be added when they were dipped in a microalgal suspension. Lack of saturation was probably owing to supply of microalgal particles. Nevertheless, microalgal densities are within some natural ranges (e.g. Hill \& Hawkins 1991) and above others (e.g. Davies et al. 1992a). Although mucus trails are thicker at their centre (J. Blackwell unpubl.) microalgal adhesion and decay showed no significant variation across the width of the trail. We offer no explanation for this save to suggest that any effect may occur beyond our $10 \mathrm{~d}$ study period.

Unlike homing limpets such as Lottia gigantea and Collisella scabra (Connor \& Quinn 1984, Connor 1986), as a non-territorial species Littorina littorea does not enhance its mucus trails with factors to aid settlement or growth of microbial populations; such would not be an evolutionarily stable strategy (see Davies et al. 1992a). Any nutritional benefit derived from trail following is likely to be serendipitous; however, this is not to say that trails are not grazed, merely that snails are not cultivating trails for feeding purposes. Further, if the trails are used, they must be used quickly. Calow (1979) showed that the short persistence times of pedal mucus reflect fast colonisation by bacteria. The breakdown is rapid, with only $\sim 25 \%$ of mucus-derived carbohydrates from Monodonta turbinata remaining on an experimental substrate after 2 tidal immersions (Herndl \& Peduzzi 1989). Chapman (1998) reported that Nodilittorina unifasciata followed fresh conspecific trails more readily than ones 2 to $3 \mathrm{~h}$ old. In the present study, all (24) fresh trails were responded to and followed by snails. Increasing the period on-shore resulted in fewer responses such that by 20 tidal cycles (10 d) only 3 of 24 trails were responded to, despite the 
mucus being visible to the experimenter. In this case we conclude that the snails could detect the trail but chose not to follow it. This choice may be based on the nutritional value of the trail or some other factor such as a desire to aggregate. Further work is required to elucidate the drive to trail follow. In the field where there are likely to be many crossing trails of varying ages, it may benefit a snail to ignore older trails and follow those that are comparatively freshly laid, be it for food, for aggregation or to find a mate. However, this study was conducted in the laboratory and the familiar (a mucus trail) might well be followed where it would not be so in the field. If snails are able to discriminate trails on terms of age, the mechanism is unknown. It may be chemosensory (Hall 1973, Bousfield et al. 1981, Stirling \& Hamilton 1986) or owing to the physical structure of the trail (Simkiss \& Wilbur 1977, Herndl \& Peduzzi 1989, Davies \& Hawkins 1998). Either mechanism might operate if snails are responding to the presence of food within the trail.

Curiously, there was no distinct preference for following trails in a particular direction (Fig. 3), despite previous results that indicated a strong preference to follow 'with polarity' (Erlandsson \& Kostylev 1995, Davies \& Beckwith 1999). In the previous studies the snails were starved, but in ours they were not. Polarity information is clearly available in trails and a lack of polarity preference could discount aggregation or mate finding as drivers for trail following. Alternatively, mucus trails may need to be in excess of $75 \mathrm{~mm}$ (the length of the slides) for polarity to be detected: the snails may have been unable to gather enough information from the trail in order to respond. Hall (1973) suggested that the mucus trails of Littorina irrorata were tested over a distance of several centimetres prior to detection of polarity.

Where animals were examined individually, starvation appeared to have no effect on foraging behaviour in our study. The speeds of snails recorded are similar to those recorded by Davies \& Beckwith (1999) for Littorina littorea. Perhaps starving for $10 \mathrm{~d}$ was not long enough to elicit a response. Unless there is intense competition for benthic food resources, it is unlikely that $L$. littorea would experience starvation for greater than $\sim 10 \mathrm{~d}$ and so is unlikely to change foraging behaviour when isolated from conspecifics. Morton et al. (1995) described how when the snail Nassarius festivus was starved (for a period $>14 \mathrm{~d}$ ), the organism changed strategy, overcoming 'fear' of predation. After a 5 wk period of starvation, pedal mucus production in the Antarctic limpet Nacella concinna dropped to $61 \%$ of the original (satiated) levels (Peck et al. 1993).

Starvation level of the tracker snail did not affect trail following. Townsend (1974) reported a positive correlation between starvation and coincidence index in
Biomphalaria glabrata, but an alternative calculation of the coincidence index was used and so the present results are difficult to compare with those of Townsend. However, snails followed the trails of starved snails for shorter distances than fed snails, suggesting that information on degree of starvation both is coded in the trails and can be detected by conspecifics. Starved snails may lay a mucus that is of different (perhaps inferior) quality in some way. It is unlikely to be of inferior quantity because locomotory mucus is expensive to produce and snails would be already likely to be conserving their mucus.

Erlandsson \& Kostylev (1995) showed that the sex of a marker Littorina littorea could be detected in the mucus. Davies \& Beckwith (1999) showed that self can also be detected. It appears that markers of satiation and trail age are also to be found in the mucus trail. The starvation level of $L$. littorea and the age of the mucus trail may be important factors determining the quantity of trail following by conspecifics. Being able to judge how well fed a conspecific is may be useful with respect to copulation and consideration of reproductive success. Trail age may be used to determine whether following that trail will lead to a likelihood of conspecific meeting for mating or aggregation, or whether grazing of the trail will be of energetic benefit. At an ecosystem level, trail following accelerates the utilisation of patchy food resources (Hawkins \& Hartnoll 1983) but clearly the degree of trail following and hence food distribution is based on accumulated choices at the level of the individual.

The discovery that the satiatory level of Littorina littorea affects the quantity of trail following has implications for previous trail-following work, which has not considered this factor. It may be necessary to reassess the work of others, relating to their treatment of snails prior to trail-following studies.

\section{LITERATURE CITED}

Bousfield JA, Tait AI, Thomas JD, Towner-Jones D (1981) Behavioural studies on the nature of stimuli responsible for triggering mucus trail tracking by Biomphalaria glabrata. Malacol Review 14:49-64

Calow P (1974) Some observations on the locomotory strategies and their metabolic effects in two species of freshwater gastropods, Ancylus fluviatilis (Mull.) and Planorbis contortus Linn. Oecologia 16:149-161

Calow P (1979) Why some metazoan mucus secretions are more susceptible to microbial attack than others. Am Nat 114:149-152

Campbell A (1994) Seashores and shallow seas of Britain and Europe. Hamlyn, London

Castenholz RW (1961) The effect of grazing on marine littoral diatom populations. Ecology 42:783-794

Chapman MG (1998) Variability in trail-following and aggregation in Nodilittorina unifasciata Gray. J Exp Mar Biol Ecol 224:49-71 
Chelazzi G (1990) Eco-ethological aspects of homing behaviour in molluscs. Ethol Ecol Evol 2:11-26

Chelazzi G, Innocenti R, Della Santina P (1983) Zonal migration and trail following of an intertidal gastropod analyzed by LED tracking in the field. Mar Behav Physiol 10: 121-136

Chelazzi G, Della Santina P, Parpagnoli D (1987) Trails following in the chiton Acanthopleura gemmata: operational and ecological problems. Mar Biol 95:539-545

Connor VM (1986) The use of mucous trails by intertidal limpets to enhance food resources. Biol Bull 171:548-564

Connor VM, Quinn JF (1984) Stimulation of food species growth by limpet mucus. Science 225:843-844

Davies MS, Beckwith P (1999) Role of mucus trails and trailfollowing in the behaviour and nutrition of the periwinkle Littorina littorea. Mar Ecol Prog Ser 179:247-257

Davies MS, Hawkins SJ (1998) Mucus from marine molluscs. Adv Mar Biol 34:1-71

Davies MS, Knowles AJ (2001) Effects of trematode parasitism on the behaviour and ecology of a common marine snail (Littorina littorea (L.)). J Exp Mar Biol Ecol 260: 155-167

Davies MS, Hawkins SJ, Jones HD (1990) Mucus production and physiological energetics in Patella vulgata L. J Molluscan Stud 56:499-503

Davies MS, Hawkins SJ, Jones HD (1992a) Pedal mucus and its influence on the microbial food supply of two intertidal gastropods, Patella vulgata L. and Littorina littorea (L.). J Exp Mar Biol Ecol 161:57-77

Davies MS, Jones HD, Hawkins S, Mill PJ, Reid DG (1992b) Pedal mucus production in Littorina littorea (L.). In: Grahame SJ (ed) Proceedings of the Third International Symposium on Littorinid Biology. The Malacological Society of London, London, p 227-233

Davies MS, Jones HD, Hawkins SJ (1992c) Physical factors affecting the fate of pedal mucus produced by the common limpet Patella vulgata L. J Mar Biol Assoc UK 72: 633-643

Denny MW (1980) Locomotion: the cost of gastropod crawling. Science 208:1288-1290

Denny MW (1989) Invertebrate mucous secretions: functional alternatives to vertebrate paradigms. In: Chantler E, Ratcliffe NA (eds) Symposia for experimental biology, no. XLIII. Mucus and related topics. The Company of Biologists, Cambridge, p 337-366

Edwards SF, Welsh BL (1982) Trophic dynamics of a mud snail [Ilyanassa obsoleta (Say)] population on an inter-tidal mudflat. Estuar Coast Shelf Sci 14:663-686

Erlandsson J, Kostylev V (1995) Trail following, speed and fractal dimension of movement in a marine prosobranch, Littorina littorea, during a mating and a non-mating season. Mar Biol 122:87-94

Føyn B (1934) Lebenszyklus, Cytologie und Sexualität der

Editorial responsibility: Otto Kinne (Editor),

Oldendorf/Luhe, Germany
Chlorophycee Cladophora suhriana Kützing. Arch Protistenkd 83:1-56

Grahame J (1973) Assimilation efficiency of Littorina littorea (L.) (Gastropoda: Prosobranchiata). J Anim Ecol 42: 383-389

Hall JR (1973) Intraspecific trail-following in the marsh periwinkle Littorina irrorata Say. Veliger 16:72-75

Hawkins SJ, Hartnoll RG (1983) Grazing of intertidal algae by marine invertebrates. Oceanogr Mar Biol 21:195-282

Herndl GJ, Peduzzi P (1989) Potential microbial utilization rates of sublittoral gastropod mucus trails. Limnol Oceanogr 34:780-784

Hill AS, Hawkins SJ (1991) Seasonal and spatial variation in epilithic microalgal distribution and abundance and its ingestion by Patella vulgata on a moderately exposed rocky shore. J Mar Biol Assoc UK 71:403-423

Lein TE (1980) The effects of Littorina littorea L. (Gastropoda) grazing on littoral green algae in the Inner Oslofjord, Norway. Sarsia 65:87-92

Morton B, Chan K (1999) Hunger rapidly overrides the risk of predation in the subtidal scavenger Nassarius siquijorensis (Gastropoda: Nassariidae): an energy budget and a comparison with the intertidal Nassarius festivus in Hong Kong. J Exp Mar Biol Ecol 240:213-228

Morton B, Chan K, Britton JC (1995) Hunger overcomes fear in Nassarius festivus, a scavenging gastropod on Hong Kong shores. J Molluscan Stud 61:55-63

Newell GE (1958) An experimental analysis of the behaviour of Littorina littorea (L.) under natural conditions and in the laboratory. J Mar Biol Assoc UK 37:241-266

Newell RC (1970) Biology of intertidal animals. Lagoon Press, London

Norton TA, Hawkins SJ, Manley NL, Williams GA, Watson DC (1990) Scraping a living: a review of littorinid grazing. Hydrobiologia 193:117-138

Peck LS, Culley MB, Helm MM (1987) A laboratory energy budget for the ormer Haliotis tuberculata L. J Exp Mar Biol Ecol 111:1-22

Peck LS, Prothero-Thomas E, Hough N (1993) Pedal mucus production by the antarctic limpet Nacella concinna (Strebel, 1908). J Exp Mar Biol Ecol 106:103-123

Peduzzi P, Herndl GJ (1991) Mucus trails in the rocky intertidal: a highly active microenvironment. Mar Ecol Prog Ser 75:267-274

Round FE, Crawford RM, Mann DG (1990) The diatoms. Cambridge University Press, Cambridge

Simkiss K, Wilbur KM (1977) The molluscan epidermis and its secretions. Symp Zool Soc Lond 39:35-76

Stirling D, Hamilton PV (1986) Observations on the mechanism of detecting mucous trail polarity in the snail Littorina irrorata. Veliger 29:31-37

Townsend CR (1974) Mucus trail following by the snail Biomphalaria glabrata (Say). Anim Behav 22:170-177

Submitted: January 15, 2002; Accepted: May 7, 2002

Proofs received from author(s): August 7, 2002 